\title{
Role of Psychology in Mental Health
}

\author{
$\mathrm{Nidhi}^{1 *}$
}

\section{ABSTRACT}

Mental health describe our social, emotional, and psychological states, all wrapped up into one. Someone who experiences "good" mental health, therefore, has found a balance in his or her social, emotional, and psychological areas of life. Term "behavioral health" is being used incorrectly refer to mental illness. We explore the nature of psychology. We outline the different schools of thought and method of inquiry in psychology. Psychologists provide vital mental and behavioral health services in primary care. They identify and modify behaviors to promote individuals' health and wellness across the lifespan. A significant and growing number of psychologists (e.g., in such areas as health, clinical, counseling, family, and rehabilitation psychology) provide inter professional, team-based care in pediatric, adult, and family-oriented primary care settings in both the public and private sectors. This paper tries to highlight the role of psychology in mental health and practically utilities of psychology in present scenario of mental health.

Keywords: Mental Health, Growing, Emotional, Explore, Wrapped.

Mental health includes "subjective well-being, perceived self-efficacy, autonomy, competence, intergenerational dependence, and self-actualization of one's intellectual and emotional potential, among others .WHO further states that the well-being of an individual is encompassed in the realization of their abilities, coping with normal stresses of life, productive work and contribution to their community. However, cultural differences, subjective assessments, and competing professional theories all affect how "mental health" is defined. Mental health is also used as a consumerist euphemism for mental illness, especially when used in conjunction with "concerns", "problems", or "clinic". Consequently, "mental health" is now being equated with mental illness without reference to the positive strengths associated with mental health, as above. Similarly, the term "behavioral health" is being used, incorrectly, to refer to mental illness, as a consumerist approach to avoiding the stigma associated with the words "mental" and "illness".

\footnotetext{
${ }^{1}$ Research scholar, Department of Psychology, M.D.U. Rohtak, India *Responding Author

(C) 2016, Nidhi; licensee IJIP. This is an Open Access Research distributed under the terms of the Creative Commons Attribution License (http://creativecommons.org/licenses/by/2.0), which permits unrestricted use, distribution, and reproduction in any Medium, provided the original work is properly cited.
} 


\section{Role of Psychology in Mental Health}

The issues of mental illness capture our interest, demand our attention, and trigger our concern. They also compel us to ask questions. To illustrate further, let's consider clinical case. Monika is a 24-year-old law student. She is attractive, neatly dressed, and clearly very bright. If you were to meet her, you would think that she had few problems in her life; but Monique has been drinking alcohol since she was 14 , and she smokes marijuana every day. Although she describes herself as "just a social drinker," she drinks four or five glasses of wine when she goes out with friends and also drinks a couple of glasses of wine a night when she is alone in her apartment in the evening. She frequently misses early morning classes because she feels too hangover to get out of bed. Although she denies having any problems with alcohol, Monique admits that her friends and family have become very concerned about her and have suggested that she seek help. The previous week she decided to stop smoking marijuana entirely because she was concerned that she might have a drug problem. However, she found it impossible to stop and is now smoking regularly again. This is a question that concerns the criteria that must be met before someone receives a particular diagnosis. These cases, which describe real people, give some indication of just how profoundly lives can be derailed because of mental disorders. It is hard to read about difficulties such as these without feeling compassion for the people who are struggling. Still, in addition to compassion, clinicians, and researchers who want to help people like If we are to understand mental disorders, we must learn to ask the kinds of questions that will enable us to help the patients and families who suffer from mental disorders.

\section{Historical view of mental illness}

Our historical efforts to understand abnormal psychology include both humor and tragedy. In this section, we will highlight some views of psychopathology, and some of the treatments administered, from ancient times to the twenty-first century. References to abnormal behavior in early writings show that the Chinese, Egyptians, Hebrews, and Greeks often attributed such behavior to a demon or god who had taken possession of a person. Whether the "possession" was assumed to involve good spirits or evil spirits usually depended on the affected individual's symptoms. If a person's speech or behavior appeared to have a religious or mystical significance, it was usually thought that he or she was possessed by a good spirit or god. Such people were often treated with considerable awe and respect, for people believed they had supernatural powers.

During this period the Greek physician Hippocrates (460-377 B.C.), often referred to as the father of modern medicine. He believed that the brain was the central organ of intellectual activity and that mental disorders were due to brain pathology. Hippocrates classified all mental disorders into three general categories-mania, melancholia, and phrenitis (brain fever)—and gave detailed clinical descriptions of the specific disorders included in each category. Later Greek and Roman physician Galen took a scientific approach to the field, dividing the causes of psychological disorders into physical and mental categories. Johann Weyer was one of the first physicians to specialize in mental disorders, and his wide experience and progressive views 


\section{Role of Psychology in Mental Health}

justify his reputation as the founder of modern psychopathology. From the sixteenth century on, special institutions called asylum - sanctuaries or places of refuge meant solely for the care of the mentally ill—grew in number, Pinel's and Tuke's humanitarian experiments revolutionized the treatment of mental patients throughout the Western world. Benjamin Rush founder of American Psychiatry. Rush encouraged more humane treatment of the mentally ill.

At the beginning of the twentieth century, National Institute of Mental Health was organized, and provided active support for research and training through psychiatric residencies and (later) clinical psychology training programs. In the first half of the twentieth century, hospital care for the mentally ill afforded very little in the way of effective treatment.

The Emergence of Contemporary Views of Abnormal Behavior what we know today as the scientific, or experimentally oriented, view of abnormal behavior and the application of scientific knowledge to the treatment of disturbed individuals. We will describe four major themes in abnormal psychology that spanned the nineteenth and twentieth centuries and generated powerful influences on our contemporary perspectives in abnormal behavior: (1) biological discoveries, (2) the development of a classification system for mental disorders, (3) the emergence of psychological causation views, and (4) experimental psychological research developments.

Advances in the study of biological and anatomical factors as underlying both physical and mental disorders developed in this period. A major biomedical breakthrough, for example, came with the discovery of the organic factors underlying general paresis-syphilis of the brain. Emil Kraepelin (1856-1926), played a dominant role in the early development of the biological viewpoint. His textbook Compendium der Psychiatrie, published in 1883, not only emphasized the importance of brain pathology in mental disorders but also made several related contributions that helped establish this viewpoint.

Despite the emphasis on biological research, understanding of the psychological factors in mental disorders was progressing as well. The first major steps were taken by Sigmund Freud (1856-1939), the most frequently cited psychological theorist of the twentieth century (Street, 1994). During five decades of observation, treatment, and writing, Freud developed a comprehensive theory of psychopathology that emphasized the inner dynamics of unconscious motives that are at the heart of the psychoanalytic perspective. The methods he used to study and treat patients came to be called psychoanalysis. The patients usually displayed considerable emotion and, on awakening from their hypnotic states, felt a significant emotional release, which was called a catharsis. One method, free association, involved having patients talk freely about themselves, thereby providing information about their feelings, motives, and so forth. A second method, dream analysis, involved having patients record and describe their dreams. These 


\section{Role of Psychology in Mental Health}

techniques helped analysts and patients gain insights and achieve a better understanding of the patients' emotional problems.

\section{Experimental Psychology}

In 1879 Wilhelm Wundt established the first experimental psychology laboratory at the University of Leipzig. While studying the psychological factors involved in memory and sensation, they followed his experimental methodology and also applied some of his research strategies to study clinical problems. Another of Wundt's students, Lightner Witmer established the first American psychological clinic. Witmer's clinic focused on the problems of mentally deficient children in terms of both research and therapy. Witmer, considered being the founder of clinical psychology. Behavioral perspective is organized around a central theme: the role of learning in human behavior. Although this perspective was initially developed through research in the laboratory rather than through clinical practice with disturbed individuals, its implications for explaining and treating maladaptive behavior soon became evident. Classical Conditioning The origins of the behavioral view of abnormal behavior and its treatment are tied to experimental work on the type of learning known as classical conditioning - a form of learning in which a neutral stimulus is paired repeatedly with an unconditioned stimulus that naturally elicits an unconditioned behavior. After repeated pairings, the neutral stimulus becomes a conditioned stimulus that elicits a conditioned response. Pavlov's discoveries in classical conditioning excited a young American psychologist, John B. Watson (1878-1958), who was searching for objective ways to study human behavior. Watson's approach placed heavy emphasis on the role of the social environment in conditioning personality development and behavior, both normal and abnormal. Today's behaviorally oriented psychologists still accept many of the basic tenets of Watson's doctrine, although they are more cautious in their claims.

Operant Conditioning E. L. Thorndike (1874-1949) and subsequently B. F. Skinner (1904-1990) were exploring a different kind of conditioning, one in which the consequences of behavior influence behavior. Behavior that operates on the environment may be instrumental in producing certain outcomes, and that behavior will be repeated on similar occasions. In Skinner's view, behavior is "shaped" when something reinforces a particular activity of an organism-which makes it possible "to shape an animal's behavior almost as a sculptor shapes a lump of clay". Here we discuss the history of mental illness see that psychology play a major role in development of mental health.

\section{How Psychologists can contribute in mental health?}

Psychologists provide vital mental and behavioral health services in primary care. They identify and modify behaviors to promote individuals' health and wellness across the lifespan. A significant and growing number of psychologists (e.g., in such areas as health, clinical, counseling, family, and rehabilitation psychology and geropsychology) provide interprofessional, team-based care in pediatric, adult, and family-oriented primary care settings in both the public and private sectors. 


\section{Role of Psychology in Mental Health}

Primary care physicians increasingly rely on the services of psychologists, particularly in rural and underserved areas. Increased access to psychologists in primary care improves the coordination of care and treatment planning, while reducing the stigma associated with seeking mental and behavioral health treatment.10

- In primary care, psychologists recognize and treat mental and behavioral health disorders earlier, often saving significant costs, decreasing the load on medical providers, and delivering services in an approach desired by many patients.13

- Psychologists provide an array of individual, group, and family interventions effective for depression, anxiety, pain, and adjustment issues surrounding chronic illness. They help patients with life-threatening illnesses manage symptoms and cope with medical interventions and their side effects. Psychologists also provide support to address family needs, enhance communication, and promote recovery.

- Formal assessment and diagnostic services delivered by psychologists provide a thorough, standardized approach to understanding the patient's presenting problem, thereby enabling appropriate treatment planning and intervention.14 Implementation of evidence-based treatment modalities by psychologists has been shown to improve both physical and mental health.9,10,15

- Research has also shown a "cost offset of 20 to 40 percent for primary care patients who receive behavioral health services.” 10 Fewer hospitalizations result in significant cost reductions for patients with chronic physical illness and/or mental health conditions.16 Access to behavioral health services during medical visits likewise improves treatment adherence,17 which has been associated with $\$ 105$ billion in annual avoidable health care costs.18

Psychologists have a strong research foundation and can contribute to the design, implementation, and evaluation of behavioral interventions that improve patients' treatment compliance and the overall management of acute and chronic health conditions in primary care.

\section{Professionals involved in the prevention, management and treatment of psychological problems}

The number of psychologists working in health and social care and other fields has increased considerably over the last few decades. Their tasks focus on preventing, assessing, treating and/or helping individuals to manage emotional, behavioural and cognitive problems using psychological theory and research. They also work alongside, or provide consultancy to, other health professionals. It is helpful to be able to distinguish between the skills available to different types of therapists who use psychology.

- Clinical psychologists aim to reduce psychological distress and enhance and promote psychological well-being. They work with people with mental or physical health problems, including anxiety and depression, serious and enduring mental illness, adjustment to physical illness, neurological disorders, addictive behaviors, and childhood behavior disorders, 


\section{Role of Psychology in Mental Health}

personal and family relationships. They work with people throughout the life span, sometimes specializing in fields such as learning difficulties.

- Health psychologists apply psychological research and methods to the strategic prevention and management of disease, the promotion and maintenance of health, the identification of psychological factors that contribute to physical illness, and the formulation of health policy. As examples, they study why and when people seek professional advice about their health, why they do or do not take preventative measures, how patients and health care professionals interact, how patients adapt to illness, and the links between perception, health behavior and physical functioning.

- Counselling psychologists apply psychology to working collaboratively with people across a diverse range of human problems. This includes helping people manage difficult life events such as bereavement, past and present relationships and mental health problems such as depression. Counselling psychologists accept subjective experience as valid for each person, explore underlying issues and use an active collaborative relationship to empower people to consider change. Counselling psychologists adopt a holistic stance, which involves examining issues within the wider context of what has given rise to them. The roles of psychologists overlap with the roles of other health care professionals who have similar aims, including:

- Counsellor. Similar to a counselling psychologist, except that anyone can describe themselves as a counsellor. Training courses vary from a few days to several years. There are short courses that provide a certificate Psychology in the context of health and social care.

- Psychoanalyst. Someone who has trained in psychoanalysis under the supervision of an approved psychoanalyst. All approved psychoanalysts can trace the provenance of their trainers back to those who were trained by Freud himself. All analysts undergo psychoanalysis themselves as part of a lengthy period of training.

- Psychodynamic psychotherapist. A therapist who has undergone a period of intensive training, including personal analysis and supervised practice, and who bases their approach on a psychodynamic model.

- Psychiatrist. A medical doctor who, since qualifying, has specialized in the diagnosis and treatment of people with mental health disorders. They may use a range of psychological therapies, but these usually include drug treatments which they have the right to prescribe. They sometimes use physical interventions such as electroconvulsive therapy (ECT). They are in charge of psychiatric beds and have the authority to admit people to hospital for treatment on a voluntary or compulsory basis. They usually assume the clinical lead of a multi professional mental health team that includes clinical psychologists, mental health nurses and social workers.

- Cognitive behavior therapist. A qualified health or social care professional, such as a mental health nurse, who has completed undergraduate or postgraduate specialist training in CBT for the treatment for such disorders as depression, psychosis or obsessive-compulsive disorders. All clinical psychologists are trained to offer CBT. 


\section{Role of Psychology in Mental Health}

\section{How to improve mental and emotional health?}

In order to maintain and strengthen your mental and emotional health, it's important to pay attention to your own needs and feelings. Don't let stress and negative emotions build up. Try to maintain a balance between your daily responsibilities and the things you enjoy. Taking care of yourself includes pursuing activities that naturally release endorphins and contribute to feeling good. In addition to physical exercise, endorphins are also naturally released when we:

- Do things that positively impact others. Being useful to others and being valued for what you do can help build self-esteem.

- $\quad$ Practice self-discipline. Self-control naturally leads to a sense of hopefulness and can help you overcome despair, helplessness, and other negative thoughts.

- Learn or discover new things. Think of it as "intellectual candy." Try taking an adult education class, join a book club, visit a museum, learn a new language, or simply travel somewhere new.

- Enjoy the beauty of nature or art. Studies show that simply walking through a garden can lower blood pressure and reduce stress. The same goes for strolling through a park or an art gallery, hiking, admiring architecture, or sitting on a beach.

- $\quad$ Limit unhealthy mental habits like worrying. Try to avoid becoming absorbed by repetitive mental habits—negative thoughts about yourself and the world that suck up time, drain your energy, and trigger feelings of anxiety, fear, and depression

- $\quad$ Appeal to your senses. Stay calm and energized by appealing to the five senses: sight, sound, touch, smell, and taste. Listen to music that lifts your mood, place flowers where you will see and smell them, massage your hands and feet, or sip a warm drink.

- Engage in meaningful, creative work. Do things that challenge your creativity and make you feel productive, whether or not you get paid for it- things like gardening, drawing, writing, playing an instrument, or building something in your workshop.

- Make leisure time a priority. Do things for no other reason than that it feels good to do them. Go to a funny movie, take a walk on the beach, listen to music, read a good book, or talk to a friend. Doing things just because they are fun is no indulgence. Play is an emotional and mental health necessity.

- Make time for contemplation and appreciation. Think about the things you're grateful for. Mediate, pray, enjoy the sunset, or simply take a moment to pay attention to what is good, positive, and beautiful as you go about your day.

Everyone is different; not all things will be equally beneficial to all people. Some people feel better relaxing and slowing down while others need more activity and more excitement or stimulation to feel better. The important thing is to find activities that you enjoy and that give you a boost.

\section{Supportive relationships: The foundation of emotional health}

No matter how much time you devote to improving your mental and emotional health, you will still need the company of others to feel and be your best. Humans are social creatures with an emotional need for relationships and positive connections to others. We're not meant to survive, let alone thrive, in isolation. Our social brains crave companionship-even when experience has made us shy and distrustful of others. Social interaction-specifically talking to someone else about your problems - can also help to reduce stress. The key is to find a supportive relationship 


\section{Role of Psychology in Mental Health}

with someone who is a "good listener"-someone you can talk to regularly, preferably face-toface, who will listen to you without a pre-existing agenda for how you should think or feel. A good listener will listen to the feelings behind your words, and won't interrupt or judge or criticize you. The best way to find a good listener? Be a good listener yourself. Develop a friendship with someone you can talk to regularly, and then listen and support each other.

\section{Acknowledgments}

The author appreciates all those who participated in the study and helped to facilitate the research process.

\section{Conflict of Interests}

The author declared no conflict of interests.

\section{REFERENCES}

E. Jane-Llopis et al., "Mental Health Promotion Works: A Review," Promotion \& Education, 13, Suppl. 2 (2005): pp. 9-25.

Everson-Rose, S. A., \& Lewis, T. T. (2005). Psychosocial factors and cardiovascular diseases. Annual Review of Public Health, 26, 469-500.

Hadan and B. Campanini (Geneva, Switzerland: World Health Organization, 2001).

Hoyert, D. L., \& Xu, J. (2012). Death: Preliminary data for 2011. National Vital Statistics Report, 61, 1-52.

Jiang, W., \& Davidson, J. R. (2005). Antidepressant therapy in patients with ischemic heart disease. American Heart Journal, 150, 871-881.

Kullowatz, A., Kanniess, F., Dahme, B., Magnussen, H., \& Ritz, T. (2007). Association of depression and anxiety with health care use and quality of life in asthma patients. Respiratory Medicine, 101, 638-644.

Luppino, F. S., de Wit, L. M., Bouvy, P. F., Stijnen, T., Cuijpers, P., Penninx, B. W. J. H. et al. (2010). Overweight, obesity, and depression: A systematic review and meta-analysis of longitudinal studies. Journal of the American Medical Association, 67, 220-229.

N. Joubert and J. Raeburn, "Mental Health Promotion: People, Power and Passion," International Journal of Mental Health Promotion (September 1998): pp. 15-22.

National Research Council. (1996). Primary care: America's health in a new era. Washington, DC: The National Academies Press.

Prince, M., Patel, V., Saxena, S., Maj, M., Maselko, J., Phillips, M.R., et al. (2007). No health without mental health. The Lancet, 370, 859-877.

R. S. Murthy et al., The World Health Report 2001: Mental Health: New Understanding, New Hope, eds.

Segerstrom, S. C., \& Miller, G. E. (2004). Psychological stress and the human immune system: A meta-analytic study of 30 years of inquiry. Psychological Bulletin, 130, 601-630.

World Health Organization, Mental Health: Strengthening Mental Health Promotion, Fact Sheet No. 220.

How to cite this article: Nidhi (2016), Role of Psychology in Mental Health, International Journal of Indian Psychology, Volume 3, Issue 4, No. 60, ISSN 2348-5396 (e), ISSN: 2349-3429 (p), DIP: 18.01.083/20160304, ISBN: 978-1-365-26308-8 